\title{
Interferon-tau promotes luteal endothelial cell survival and inhibits specific luteolytic genes in bovine corpus luteum
}

\author{
Raghavendra Basavaraja ${ }^{1}$, Emilia Przygrodzka², Bartosz Pawlinski ${ }^{3}$ Zdzislaw Gajewski ${ }^{3}$, \\ Monika M Kaczmarek ${ }^{2,3}$ and Rina Meidan ${ }^{1}$ \\ ${ }^{1}$ Department of Animal Sciences, The Robert H Smith Faculty of Agriculture, Food and Environment, The Hebrew \\ University of Jerusalem, Rehovot, Israel, ${ }^{2}$ Institute of Animal Reproduction and Food Research, Polish Academy of \\ Sciences, Olsztyn, Poland, and ${ }^{3}$ Department for Large Animal Diseases, Faculty of Veterinary Medicine, University \\ of Life Sciences, Warsaw, Poland \\ Correspondence should be addressed to R Meidan; Email: rina.meidan@mail.huji.ac.il
}

\begin{abstract}
Interferon-tau (IFNT), a maternal recognition of pregnancy (MRP) signals in domestic ruminants, suppresses the release of luteolytic pulses of uterine prostaglandin F2a (PGF2a), thus extending the corpus luteum (CL) life span. We hypothesized that IFNT also exerts anti-luteolytic actions in bovine CL. To examine the direct effects of IFNT on bovine CL, luteal slices and enriched luteal endothelial cells (LECs) were utilized. We found that recombinant ovine IFNT (roIFNT) markedly elevates interferon-associated genes (STAT1, STAT2 and IRF9) and interferon-stimulated genes (ISGs: MX2, ISG15 and OAS1 Y) in both models. Furthermore, IFNT timedependently induced STAT1 phosphorylation in LECs without affecting total STAT1. roIFNT-stimulated viable LECs numbers and the knockdown of protein inhibitor of activated STAT1 (PIAS1) abolished this effect, suggesting that PIAS1 may mediate the proliferative effect of IFNT. IFNT significantly downregulated luteolytic genes such as TGFB1, thrombospondin-1 (THBS1), endothelin-1 (EDN1) and serpin family E member-1 (SERPINE1) in LECs. However, less robust effects were observed in luteal slices. Moreover, PGF2a alone induced THBS1, SERPINE1 and EDN1 mRNA in CL slices whereas in the presence of IFNT, THBS1 and SERPINE1 stimulation was abolished. Collectively, these results indicate that IFNT acts via STAT1- IRF9-dependent and independent pathways and affects diverse luteal functions. Most interestingly, this study suggests the existence of an anti-luteolytic effect of IFNT in bovine CL, namely, inhibiting key PGF2a-induced luteolytic genes. The proliferative effect of IFNT may constitute an additional mechanism that promotes luteal cell survival, thus, extending the luteal life span during early pregnancy in cows.

Reproduction (2017) 154 559-568
\end{abstract}

\section{Introduction}

Maternal recognition of pregnancy (MRP) is a prerequisite for the successful establishment of pregnancy and maintenance of the corpus luteum $(\mathrm{CL})$ function. In ruminants, the mononuclear trophectoderm of the conceptus secretes interferon-tau (IFNT) during the peri-implantation period, which serves as the MRP signal (Spencer et al. 1996, Roberts et al. 1999). Bovine IFNT transcripts were detected in uterine flushes in samples from days 12-28 (Takahashi H. et al. 2007), also prevents secretion of luteolytic pulses of prostaglandin f2 alpha (PGF2a) by uterine epithelia and blocks effects of exogenous estradiol and oxytocin to stimulate uterine release of PGF2a. Expression of estrogen receptor 1 (ESR1) and oxytocin receptor (OXTR) mRNAs is either silenced or the receptors are not responsive to estradiol and oxytocin in endometria of both pregnant cows and cyclic cows treated with intrauterine injections of IFNT (Thatcher et al. 1989, Meyer et al. 1995). In this way, it prevents the release of luteolytic pulses of PGF2a from the endometrium and allows the prolongation of the CL life span and progesterone (P4) production. Recent studies performed by Arosh and coworkers also emphasized the role of the prostaglandin transporter (PGT), in the transport of PGF2a from the endometrium to the ovary (Banu et al. 2010, Lee et al. 2010).

In the absence of a functional/live conceptus in the uterus, the $\mathrm{CL}$ undergoes luteolysis (Niswender et al. 2000, Schams \& Berisha 2004). Recent evidence highlighted certain genes such as endothelin1 (END1), transforming growth factor beta1 (TGFB1), thrombospondin1 (THBS1) and serpin family $E$ member1 (SERPINE1) are specifically induced during luteolysis in the PGF2a-responsive CL (Miyamoto et al. 1997, Kliem et al. 2007, Hou et al. 2008, Mondal et al. 2011, Romero et al. 2013, Farberov \& Meidan 2016). Their gene products are expected to promote vascular instability, as well as apoptosis and matrix remodeling in the regressing CL. These genes are highly expressed 
in luteal endothelial cells (LECs) (Levy et al. 2001, Zalman et al. 2012). Moreover, prostaglandin F receptor (PTGFR) that are present in LECs (Mamluk et al. 1998, Zannoni et al. 2007, Lee et al. 2010, Shirasuna et al. 2012), can mediate direct PGF2a actions on some of these genes (Girsh et al. 1996b, Shirasuna et al. 2008, Zalman et al. 2012).

IFNT may also act as an endocrine hormone, inducing the expression of several interferon-stimulated genes (ISGs; ISG 15, MX1 and 2, OAS1Y and others) in extra-uterine tissues such as the $\mathrm{CL}$, peripheral blood cells and the mammary gland (Oliveira et al. 2008, Yang et al. 2010, Nitta et al. 2011, Matsuyama et al. 2012). Indeed, the uterine infusion or endocrine delivery of recombinant ovine (rolFNT) via the uterine or jugular vein extended the life span of $C L$ in ewes (Oliveira et al. 2008, Bott et al. 2010, Antoniazzi et al. 2013). However, the underlying mechanism that mediates $C L$ rescue has not been established yet. To gain a better understanding about IFNT-induced luteal events that may prevent luteolysis of bovine $\mathrm{CL}$ during MRP, we investigated the direct effects of IFNT on whole luteal tissue, using $\mathrm{CL}$ slices and on LECs, a specific cell type within the CL.

\section{Materials and methods}

Unless otherwise stated, all biochemicals were from SigmaAldrich and the cell culture materials were from Biological Industries (Kibbutz Beit Haemek, Israel).

\section{Isolation and culture of LECs}

The procedures for isolation and enrichment of LECs were detailed previously (Levy et al. 2001, Farberov \& Meidan 2014, 2016). Briefly, CL was dispersed using sequential incubations with collagenase. Then cells were incubated with BS-1-coated magnetic beads. The adherent cells were washed and concentrated using a magnet until the supernatant was free of cells. BS-1-positive cells (enriched LECs fraction) were plated in DMEM/F-12 containing 10\% fetal calf serum (FCS) on collagen type I-coated plates (Surecoat; Advanced BioMatrix). Colonies of LECs were trypsinized with $1 \%$ crystalline trypsin (Biological Industries), collected and reseeded; this process was repeated until homogenous cell cultures were visualized. Cell identity was verified using endothelial cell markers (CD31, EDN1) and the lack of contamination by smooth muscle cells (ACTAG2 expression) and fibroblasts (COL1A1 expression) was evaluated. Cells from passages $7-10$, derived from at least three different CLs, were used in the present study. The LECs were seeded in 12-well plates (70,000 cells/well) and cultured overnight in DMEM/F-12 containing 10\% FCS. The next day, the cells were transferred to starvation medium $0.5 \%$ BSA in $0.1 \%$ FCS) for $24 \mathrm{~h}$. Then, the LECs were incubated for the time indicated in the legends with or without rolFNT (0.01-10 ng/ $\mathrm{mL}$; a generous gift from Prof. Fuller W Bazer, Texas A\&M University). At the end of the incubation period, the total RNA was extracted from the cells.

\section{Experimental animals and synchronization}

Holstein Friesian primiparous cows from commercial dairy farms in central Poland were utilized in this experiment. The experimental protocols and procedures were approved by the Local Ethics Committee. Cows received two intramuscular injections of PGF2a $(5 \mathrm{~mL}$ dinolytic $5 \mathrm{mg} /$ $\mathrm{mL}$, Zoetis, Belgium) 11 days apart. Estrus was detected 24-72 h after the second PGF2a administration and reproductive tracts including ovaries were monitored by transrectal ultrasonography using a $5-8 \mathrm{MHz}$ linear-array probe (MyLabOne VET, Italy) throughout the experiment. At mid-luteal phase (days 12-14 of the estrous cycle), ovaries with CL were surgically removed under anesthesia. Four CLs derived from individual cows were harvested and used for the experiment described below.

\section{Culture of $C L$ slices}

$\mathrm{CL}$ (above) was cut into slices $(300 \mu \mathrm{m}$ thick, $8 \mathrm{~mm}$ diameter, 10-15 mg wet weight) using a Krumdick Tissue Slicer (K\&F Research, Birmingham, AL, USA) as previously described (Przygrodzka et al. 2014). Then, the slices (2 slices/well) were incubated for $12 \mathrm{~h}$ in $\mathrm{M}$-199 supplemented with $0.1 \%$ bovine serum albumin (BSA; ICN Bio Medicals, Inc., Costa Mesa, CA, USA), antibiotics (penicillin-streptomycin; Sigma-Aldrich) and an anti-fungal drug (amphotericin B; Sigma-Aldrich) in the presence or absence of rolFNT $(1 \mathrm{ng} / \mathrm{mL})$ or PGF2a (Cayman Chemical; $30 \mathrm{nM}$ ) alone or in combination of rolFNT and PGF2a. Each treatment (for each cow) was examined in duplicates and averaged. At the end of the incubation, slices were collected, rapidly frozen in liquid nitrogen and stored at $-80^{\circ} \mathrm{C}$ until total RNA isolation.

\section{Western blot analyses}

Proteins were extracted by adding sample buffer $(\times 2)$, separated by $7.5 \%-12.0 \%$ SDS-PAGE, and subsequently transferred to nitrocellulose membranes, as previously reported (Zalman et al. 2012). Membranes were blocked for $1 \mathrm{~h}$ in TBST $(20 \mathrm{mmol} / \mathrm{L}$ Tris, $150 \mathrm{mmol} / \mathrm{L} \mathrm{NaCl}$ and $0.1 \%$ Tween 20 ; $\mathrm{pH} 7.6$ ) containing $3 \%$ BSA or $5 \%$ low-fat milk and then incubated overnight at $4{ }^{\circ} \mathrm{C}$ with the following antibodies: goat polyclonal phosphorylated STAT1 (TYR701; 1:200; sc-7988R; Santa Cruz Biotechnology); goat polyclonal STAT1 (1:200; sc-346-G; Santa Cruz Biotechnology); mouse anti-THBS1 (1:500; ab1823; Abcam) and rabbit anti-p44/42 total MAPK (1:50,000; Sigma-Aldrich). The membranes were then incubated with peroxidase-conjugated goat anti-rabbit IgG (Jackson ImmunoResearch) or goat anti-mouse immunoglobulin G (heavy + light) (ab6789; Abcam) for $1 \mathrm{~h}$ at room temperature. A chemiluminescent signal was generated with SuperSignal (Thermo Fisher Scientific), and the membranes were exposed. The signal was analyzed using the Gel-Pro Analyzer version 3.0 (Media Cybernetics, Inc., MD, USA) and normalized to total p44/42 MAPK in the same sample to correct for the amount of protein loaded. 


\section{Transfection of LECs}

Cells were seeded for overnight in 24-well (16,000 cells/ well) plates containing $500 \mu \mathrm{L}$ of DMEM/F-12 medium comprising $10 \%$ FCS. The next day, cells were transfected with siRNA ( $50 \mathrm{nmol} / \mathrm{L}$; GeneCust, Luxembourg; as previously described (Farberov \& Meidan 2016). siRNA targeting protein inhibitor of activated STAT1 (PIAS1) and scrambled siRNA (negative control; $50 \mathrm{nmol} / \mathrm{L}$ ) using $3.6 \mu \mathrm{L}$ of lipofectamine 2000 reagent (Invitrogen) according to the manufacturer's protocol at $1 \%$ FCS. The siRNA of PIAS1 (siPIAS1) was sense (S) GAGACAAUCAGCACUAUAA dCdA, antisense (AS) UUAUAGUGCUGAUUGUCUCdCdT, corresponding to bases 1664-1684 (NM_001075396.2). Scrambled siRNA sequencenegative control was (S) UUCUCCGAACGUGUCACGUdTdT and (AS) ACGUGACACGUUCGGAGAAdTdT. After $24 \mathrm{~h}$ post transfection, LECs were transferred to starvation medium and the next day they were treated with or without IFNT $(1 \mathrm{ng} / \mathrm{mL})$ for $24 \mathrm{~h}$.

\section{Determination of the viable cell numbers}

The viable cell numbers were estimated as previously described (Farberov \& Meidan 2014), using the XTT kit (Biological Industries), which measures the reduction of a tetrazolium component by the mitochondria of viable cells. On the day of measurement, XTT was added to the culture media according to the manufacturer's instructions. Then, plates were incubated at $37^{\circ} \mathrm{C}$ for $2-3 \mathrm{~h}$. Afterwards, the absorbance was read at $450 \mathrm{~nm}$ (reference absorbance, $630 \mathrm{~nm}$ ).

\section{RNA extraction and qRT-PCR}

\section{CL slices}

Collected luteal tissue samples were homogenized in Tri Reagent (Molecular Research Center) with a FastPrep-24 instrument (MP Biomedical, Santa Ana, CA, USA). Total RNA was extracted by using the RNeasy Mini Kit (Qiagen) according to the manufacturer's protocol. The integrity and quality of RNA were verified using the Agilent 2100 Bioanalyzer (Agilent Technologies) and NanoDrop (Thermofisher). Genomic DNA contamination was removed according to the manufacturer's instructions (DNAse I Kit, Thermofisher). Gene expression was evaluated by one-step real-time PCR using the Applied

Table 1 Genes, Genbank accessions and TaqMan Assays' ID used in real-time PCR for luteal tissue slices.

\begin{tabular}{lll}
\hline Gene name & TaqMan Assay ID & Accession no. \\
\hline GAPDH & Bt03210919_g1 & NM_001034034 \\
STAT1 & Bt03252661_m1 & NM_001077900.1 \\
STAT2 & Bt04284638_m1 & NM_001205689.1 \\
IRF9 & Bt03220019_m1 & NM_001024506.1 \\
MX2 & Bt03211948_m1 & NM_173941.2 \\
ISG15 & Bt03223508_m1 & NM_174366.1 \\
OAS1Y & Bt03211516_m1 & NM_001040606.1 \\
TGFB1 & Bt04259488_m1 & NM_001166068 \\
THBS1 & Bt03213209_m1 & NM_174196 \\
SERPINE1 & Bt03212914_m1 & NM_174137 \\
EDN1 & Bt03217448_m1 & NM_181010.2 \\
\hline
\end{tabular}

Biosystems 7900 HT Sequence Detection System (Applied Biosystems) with TaqMan assays (Thermofisher; Table 1). As detailed previously, each qPCR was performed in duplicates on 384-well plates and was preceded by a reverse transcription reaction $\left(15 \mathrm{~min}\right.$ at $40^{\circ} \mathrm{C}$ ) (Przygrodzka et al. 2016). To select the most stable housekeeping gene among glyceraldehyde 3-phosphate dehydrogenase $(G A P D H)$, betaactin (ACTB) and hypoxanthine phosphoribosyltransferase 1(HPRT), the NormFinder algorithm was applied, based on the report and GAPDH was chosen as a housekeeping gene (Andersen et al. 2004). The expression of selective genes was normalized relative to the abundance of GAPDH mRNA. The threshold cycle number $(\mathrm{Ct})$ was used to quantify the relative abundance of the gene; arbitrary units were calculated as $2^{-\Delta \mathrm{Ct}}=2^{-(\mathrm{Ct} \text { target gene-Ct housekeeping gene) }}($ Livak \& Schmittgen 2001).

\section{LECS}

Total RNA was isolated from cells using Tri Reagent (Molecular Research Center, Cincinnati, OH, USA) according to the manufacturer's instructions. As previously described, total RNA was reverse transcribed and quantitative RT-PCR (qPCR) was performed using the LightCycler 96 system (Roche Diagnostics) with Platinum SYBR Green (SuperMix, Invitrogen) (Farberov \& Meidan 2016). The sequence of primers used for quantitative RT-PCR (qPCR) is listed in Table 2. All primers were designed to have single-product melting curves, as well as consistent amplification efficiencies between 1.8 and 2.2 (Schmittgen \& Livak 2008). All amplicons were verified by sequencing. To select the most stable housekeeping gene among glyceraldehyde 3-phosphate dehydrogenase (GAPDH) and ribosomal protein S26 (RPS26) in LECs, the NormFinder

Table 2 Genes, Genbank accessions and the sequences of primers used for real-time PCR performed in LECs.

\begin{tabular}{|c|c|c|}
\hline Gene name & Sequence $\left(5^{\prime}-3^{\prime}\right)$ & Accession no. \\
\hline GAPDH & $\begin{array}{l}\text { f-gtcttcactaccatggagaagg } \\
\text { r-tcatggatgaccttggccag }\end{array}$ & NM_001034034 \\
\hline RPS26 & $\begin{array}{l}\text { f-ccaactgtgcccgatgtg } \\
\text { r-ttcc gagagcgattcctga }\end{array}$ & NM_001015561 \\
\hline IFNAR1 & $\begin{array}{l}\text { f-gtagtgggtggccgaaag } \\
\text { r-tgctgctgttccacttcagga }\end{array}$ & NM_174552.2 \\
\hline STAT1 & $\begin{array}{l}\text { f-cagccagctcccaagtg } \\
\text { r-gccaactcagcacctctg }\end{array}$ & NM_001077900.1 \\
\hline IRF9 & $\begin{array}{l}\text { f-agcagcaacagccctgag } \\
\text { r-gcccgttgtagatgaagg }\end{array}$ & NM_001024506.1 \\
\hline PIAS1 & $\begin{array}{l}\text { f-ggcatactgagtcttccacatcaag } \\
\text { r-tgctgcagcaaggagggaggtgt }\end{array}$ & NM_001075396.2 \\
\hline$M \times 2$ & $\begin{array}{l}\text { f-tggcaggtggaagagagc } \\
\text { r-gagtcgatgaggtcaatgcag }\end{array}$ & NM_173941.2 \\
\hline ISG15 & $\begin{array}{l}\text { f-ggtatccgagctgaagcagtt } \\
\text { r-acctccctgctgtcaaggt }\end{array}$ & NM_174366.1 \\
\hline OASTY & $\begin{array}{l}\text { f-tttggtctggctggattacc } \\
\text { r-taggctggaacatcaggtc }\end{array}$ & NM_001040606.1 \\
\hline TGFB1 & $\begin{array}{l}\text { f-caggaccttgctgtactgtg } \\
\text { r-gagccctggacaccaactac }\end{array}$ & NM_001166068 \\
\hline THBS1 & $\begin{array}{l}\text { f-atcatggctgactcaggac } \\
\text { r-taagcccatggttccagaa }\end{array}$ & NM_174196 \\
\hline SERPINE1 & $\begin{array}{l}\text { f-cagaaggtgaagattgaggtg } \\
\text { r-ggcccatgaacaggacagttcc }\end{array}$ & NM_174137 \\
\hline EDN1 & $\begin{array}{l}\text { f-ctgccacctggacatcatttg } \\
\text { r-tctcacggtctgttgcctttg }\end{array}$ & NM_181010.2 \\
\hline
\end{tabular}


algorithm was applied, based on the report, RPS26 was chosen as a housekeeping gene (Andersen et al. 2004). The expression of selective genes was normalized relative to the abundance of RPS26 mRNA.

\section{Statistical analyses}

All statistical analyses were conducted using GraphPad Prism version 4.03 Software (GraphPad Software). Data are presented as the means of \pm S.E.M.; LECs culture experiments were repeated at least three times; $C L$ slices were collected from four different mid-luteal phase (days 12-14th of the estrous cycle) cows and incubated separately. The expressions of selective mRNA levels were normalized to the relative abundance of GAPDH (for luteal slices) and RPS26 (for LECs). Data were analyzed by either Student's t-test or one-way ANOVA, followed by Bonferroni's post hoc multiple comparison test, when indicated. Differences were considered as significant at $P<0.05$. Asterisks or different letters represent statistical significant differences $(P<0.05)$. Additional information is provided in legends to figures.

\section{Results \\ IFNT induces ISGs, IFN-associated genes and STAT1 phosphorylation in LECs}

We first examined whether IFNT induces the expression of classical ISGs such as ISG 15, MX2 and OAS1Y mRNA in LECs. As shown in Fig. 1 (A, B and C), rolFNT (0.01$10 \mathrm{ng} / \mathrm{mL})$ elevated $M X 2(P<0.001)$, ISG $15(P<0.001)$ and OAS1Y $(P<0.001)$ levels in LECs in a dosedependent manner. Among these ISGs, MX2 exhibited the highest induction by rolFNT, followed by ISG15 and OAS1Y (Fig. 1A, B and C).

We then examined STAT1 phosphorylation by IFNT. As shown in Fig. 2, $1 \mathrm{ng} / \mathrm{mL}$ of rolFNT significantly induced tyrosine 701 phosphorylation already within $15 \mathrm{~min}$ $(P<0.05)$. STAT1 phosphorylation was evident between 15 and $60 \mathrm{~min}$ and its highest induction in response to rolFNT was observed after 60 min of LECs treatment with IFNT $(P<0.001)$, the response markedly dropped after $120 \mathrm{~min}$ (Fig. 2). The content of total STAT1 remained unchanged throughout treatment with IFNT (Fig. 2). The effect of $1 \mathrm{ng} / \mathrm{mL}$ rolFNT on mRNA expression of the
IFN-associated genes IFNAR1, STAT1, IRF9 and PIAS1 in LECs is shown in Table 3. IFNT markedly elevated as compared to control treatment: STAT1 (5.3-fold; $P<0.01$ ), IRF9 (8.6-fold; $P<0.001$ ) and PIAS1 (1.8-fold; $P<0.01)$ mRNA levels. However, IFNAR1 levels in LECs remained unaffected after the treatment with IFNT.

\section{IFNT regulates LECs function}

To examine whether IFNT is functionally important for the survival of LECs, we assayed the cells viability. rolFNT doubled viable LECs numbers as compared with the control group (cells cultured in basal medium;Fig. 3A). Since PIAS1 is known to be involved in cell proliferation (Munarriz et al. 2004), we examined the effect of PIAS1 silencing on IFNT-induced cell proliferation. IFNT maintained its stimulatory effect (1.5 folds) on viable cell numbers with scrambled siRNA transfection (Fig. 3C). However, PIAS1 siRNA significantly reduced PIAS1 mRNA (basal as well as rolFNT-stimulated levels) by $60-70 \%$ (Fig. 3B). Concurrently with the decrease in PIAS1 mRNA, cell viability was significantly reduced by PIAS1 silencing (compared with cells transfected with a scrambled siRNA-negative control; Fig. 3C). Furthermore, the positive effect of rolFNT on LECs viability was abolished in PIAS1-silenced cells (Fig. 3C). IFNT had an additional important effect on LECs, i.e., incubation of these cells for $24 \mathrm{~h}$ with $1 \mathrm{ng} / \mathrm{mL}$ of rolFNT reduced the mRNA levels of luteolytic genes: TGFB1 $(\sim 25 \% ; \quad P<0.01)$, THBS1 $(\sim 36 \% ; P<0.001), \quad$ EDN1 $(\sim 40 \% ; P<0.001)$ and SERPINE1 ( 50\%; $P<0.001)$ (Fig. 4A). THBS1 protein levels in LECs were also strongly reduced (by 60\%) in cells incubated with rolFNT (Fig. 4B).

\section{Effects of IFNT, PGF2a and their combination in CL slices}

$\mathrm{CL}$ slices were treated with $1 \mathrm{ng} / \mathrm{mL}$ of rolFNT for $12 \mathrm{~h}$ as detailed in the materials and methods section. As shown in Fig. 5A, B, C, D, E and F, rolFNT-elevated STAT1 (2.2fold; $P<0.01)$, STAT2 (6.0-fold; $P<0.01)$, IRF9 (6.1-fold; $P<0.001)$, MX2 (230-fold; $P<0.01)$, ISG15 (30-fold; $P<0.01)$ and OAS1Y (260-fold; $P<0.001)$ mRNA levels
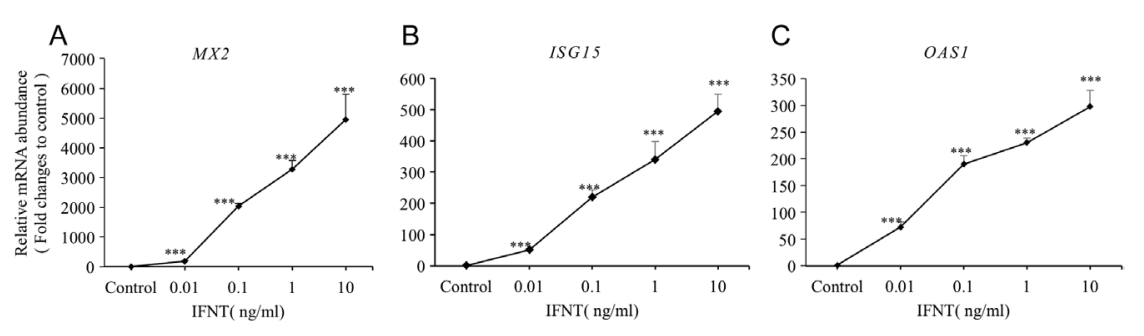

Figure 1 Dose-dependent effect of IFNT on MX2 (A), ISG15 (B) and OAS1Y (C) mRNA expression in LECs. Serum-starved cells were incubated for $24 \mathrm{~h}$ with either basal media (control) or varying concentrations of rolFNT $(0.01-10 \mathrm{ng} / \mathrm{mL})$. Cells were then harvested and mRNA expression was determined using quantitative PCR (qPCR). The results are presented as the means \pm S.E.M. of 4 independent experiments. Asterisks indicate significant $\left({ }^{*} P<0.05,{ }^{* *} P<0.01,{ }^{* * *} P<0.001\right)$ statistical differences from their respective controls. 

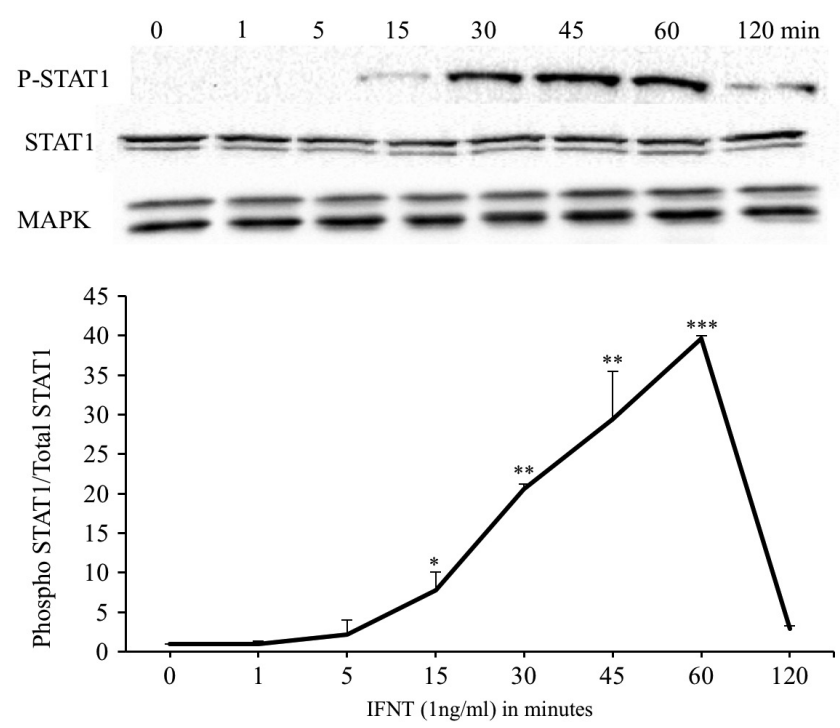

Figure 2 Time-dependent effect of IFNT on STAT1 tyrosine phosphorylation. Whole cell extracts from serum-starved LECs were incubated with IFNT (1 ng/mL) for different time points as indicated. Tyrosine phosphorylated STAT11 (p-STAT1) and total STAT1 proteins were analyzed using specific antibodies in western blotting. Phospho-STAT1 and total STAT1 were normalized relative to the abundance of total MAPK (p44/42). The results represent the means \pm S.E.M. of 4 independent experiments. Asterisks indicate significant $\left({ }^{*} P<0.05,{ }^{* *} P<0.01,{ }^{* * *} P<0.001\right)$ statistical differences from time 0 .

as compared to controls. To determine the anti-luteolytic effects of rolFNT in whole bovine $\mathrm{CL}$ tissue, slices were incubated with IFNT, PGF2a and their combination (Fig. 6). Similar to the responses observed in LECs, there was a significant downregulation of TGFB1 $(17 \%$; $P<0.05)$, THBS1 (25\%; $P<0.05)$ and SERPINE1 $(30 \%$; $P<0.001)$ mRNAs in rolFNT-treated $\mathrm{CL}$ slices (Fig. 6). PGF2a significantly stimulated THBS1 $(137 \% ; P<0.01)$, SERPINE1 (138\%; $P<0.01)$ and EDN1 $(134 \% ; P<0.01)$. Importantly, the stimulation of THBS1 and SERPINE1 induced by PGF2a alone was abolished in the presence of IFNT. TGFB1 expression was significantly reduced by the combined treatment of IFNT and PGF2a (32\%; $P<0.001$ ), although there was no induction by PGF2a alone. Contrary to LECs, the expression of EDN1 was stimulated by rolFNT alone or in presence of PGF2a (Fig. 6). Similar, but less pronounced, effects of IFNT were also observed in LECs cultured for $12 \mathrm{~h}$ (data not shown).

Table 3 The expression of IFNAR1, STAT1, IRF9 and PIAS1 in LECs cultured for $24 \mathrm{~h}$ with roIFNT $(1 \mathrm{ng} / \mathrm{mL})$.

\begin{tabular}{lll}
\hline Genes & \multicolumn{1}{c}{ IFNT } & $\boldsymbol{P}$ value \\
\hline IFNAR1 & $0.84 \pm 0.08$ & 0.203 \\
STAT1 & $5.32 \pm 0.87$ & 0.01 \\
IRF9 & $8.66 \pm 0.36$ & 0.00001 \\
PIAS1 & $1.88 \pm 0.77$ & 0.007 \\
\hline
\end{tabular}

Results are the means \pm S.E.M. $(n=4)$; the expression of each gene is relative to its respective controls designated as 1 .

\section{Discussion}

The present study demonstrates that IFNT affects diverse luteal functions in cows: it stimulated the expression of ISGs, IFN-associated genes, STAT1 phosphorylation, LECs survival and suppressed key luteolytic genes. These actions together may contribute to the maintenance of the bovine $\mathrm{CL}$ during early pregnancy.

It was previously shown that several ISGs are stimulated in the CL of ovine and bovine species during early pregnancy (Oliveira et al. 2008, Magata et al. 2012), or after IFNT infusion in ewes (Bott et al. 2010). A direct in vitro effect of IFNT on various luteal cell types was also demonstrated in several studies (Oliveira et al. 2008, Yang et al. 2010, Nitta et al. 2011, Antoniazzi et al. 2013, Romero et al. 2015, Shirasuna et al. 2015). In the present study, we showed that rolFNT dose-dependently stimulated ISGs (MX2, ISG15 and OAS1Y) expression in cultured luteal slices as well as in LECs of bovine CL. Taken together, these results support the contention that IFNT acts directly on bovine $\mathrm{CL}$ to stimulate ISGs expression.

IFNT is a multifunctional cytokine that exhibits biological activity similarly to other type-1 IFNs. It acts via binding to the cell surface receptors IFNAR1 and IFNAR2 (Rosenfeld et al. 2002). It is well established that IFNT activates the classical JAK-STAT-IRF signaling pathway in the ruminant endometrium (Staggs et al. 1998, Vitorino Carvalho et al. 2016). Based on these studies, a model has been proposed in which the tyrosine phosphorylation of STAT1 elicited by IFNT leads to the formation of STAT1-STAT2-IRF9 heterotrimers, also known as IFN-stimulated gene factor 3 complex (ISGF3), which is translocated to the nucleus and binds to the interferon-stimulated response element (ISRE) present within the promoter of ISGs and regulates their expression (Vitorino Carvalho et al. 2016). However, IFNT signaling has not yet been validated in tissues other than the endometrium. Findings reported in the present study clearly showed that rolFNT can induce temporal STAT1 phosphorylation and that rolFNT stimulates the expression of interferon-associated genes such as STAT1, STAT2 and IRF9 in LECs and luteal tissue slices. Thus, it seems likely that IFNT-dependent induction of ISGs in the bovine CL occurs via the STAT1-IRF9 pathway.

PIAS proteins are a family of four multifunctional proteins (PIAS1-4), which are known to be important regulators of cytokine actions (Sharrocks 2006). PIAS1 regulates the JAK/STAT pathway by interfering with the DNA binding activity of activated STAT1 (Liu et al. 2004). PIAS1 also acts in a STAT-independent manner to promote mammalian cell proliferation by inhibiting p53 and p73 transcriptional activity (Munarriz et al. 2004). Using LECs, we showed that rolFNT induced PIAS1 expression and increased viable cell numbers. Moreover, PIAS1 silencing abolished rolFNT-elevated cell proliferation without affecting IFNT-induced ISGs 

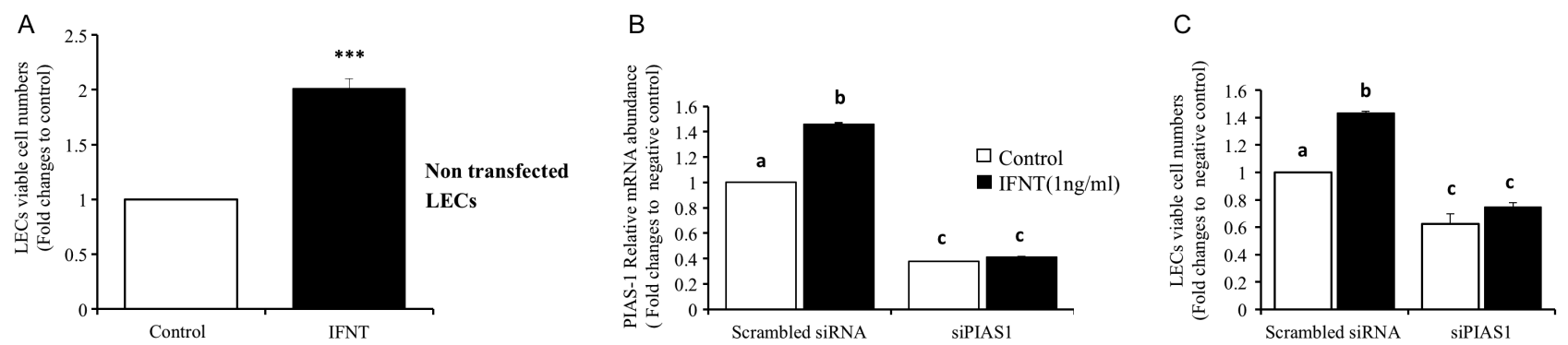

Figure 3 Role of PIAS1 in IFNT-induced LEC viability. (A) Non-transfected LEC. (B) PIAS1 mRNA expression and (C) LECs numbers in cells transfected with PIAS1 siRNA (siPIAS1) or scrambled siRNA. (A) Overnight serum-starved LECs were treated with rolFNT (1 ng/mL) for $24 \mathrm{~h}$ followed by cell viability determination using XTT. B and C-LECs were transfected with either scrambled siRNA or specific siPIAS1. 24h post transfection, cells were starved overnight, followed by incubation with or without IFNT $(1 \mathrm{ng} / \mathrm{mL})$ for additional $24 \mathrm{~h}$. Control- cell cultured in basal media (without IFNT). The results are presented as the means \pm S.E.M. from 4 independent experiments. Asterisks indicate significant statistical differences from their respective controls at ${ }^{* * *} P<0.001$ (Student's $t$-test). The different letters indicate significant statistical differences at $P<0.05$ analyzed using ANOVA followed by Bonferroni's post hoc multiple comparison test.

(data not shown) thus, suggesting STAT-independent action of IFNT in the bovine CL. These findings underscore the importance of PIAS1 in mediating the stimulatory effect of IFNT on LECs survival. Antoniazzi and coworkers (Antoniazzi et al. 2013) demonstrated that endocrine delivery of IFNT upregulated cell survival genes such as BCL2-like 1 (BCL2L1 or Bcl-xL), serine/ threonine kinase (AKT), X-linked inhibitor of apoptosis (XIAP) in ewes CL. These genes were inhibited during luteolysis by PGF2a (Antoniazzi et al. 2013). These findings together with the current data support the role of IFNT as survival factor for luteal cells.

It was shown that the luteolytic cascade, initiated by PGF2a, involves the luteal stage and the time-dependent induction of several key genes within the CL: EDN1, THBS1, TGFB1 and SERPINE1 are among the most extensively studied (Girsh et al. 1996a, Shirasuna et al. 2004, Choudhary et al. 2005, Maroni \& Davis 2012, Romero et al. 2013, Meidan et al. 2017). These factors act in concert to inhibit $\mathrm{P} 4$ production, angiogenic support, cell survival and extracellular matrix (ECM) remodeling to achieve $\mathrm{CL}$ regression as described below. EDN1 and P4 curves showed a close, inverse relationship in response to luteolytic dose of PGF2a (Ohtani et al. 1998) suggested that luteal EDN1 may be the local mediator of PGF2a in reducing P4 output. Indeed, EDN1 was shown to directly inhibit basal and $\mathrm{LH}$-induced $\mathrm{P} 4$ in many species, acting via selective EDNRA (Miyamoto et al. 1997, Apa et al. 1998, Meidan et al. 2005). During early pregnancy luteal EDN1 was inhibited (Costine et al. 2007, Przygrodzka et al. 2016). PGF2 $\alpha$ administration at mid-cycle elevated the expression of several antiangiogenic, pro-apoptotic genes, including THBS1 and TGFB1 (Hou et al. 2008, Mondal et al. 2011, Zalman et al. 2012, Romero et al. 2013, Berisha et al. 2016, Farberov \& Meidan 2016). THBS1 was shown to be a physiological activator of latent TGFB1 in LECs (Farberov \& Meidan 2016). Both THBS1 and TGFB1 triggered apoptosis, but THBS1 was significantly more effective in causing cell death and activating caspase-3. THBS1 and TGFB1 also differed in their activation of p38 mitogen-activated protein kinase (Farberov \& Meidan 2016). Similarly to THBS1 and TGFB, SERPINE1 showed marked luteal stage specific expression with extensive responses to PGF2a at mid-cycle (Smith et al. 1997, Kliem et al. 2007, Berisha et al. 2016, Farberov \& Meidan 2016). SERPINE1 is known to be a downstream target of TGFB1; it encodes endothelial PAI-1, a member
A

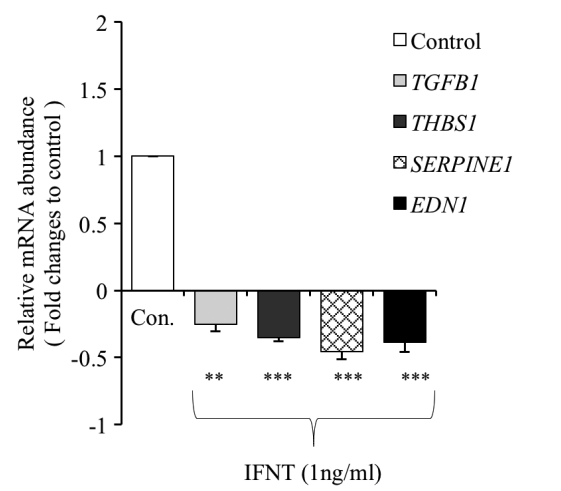

B

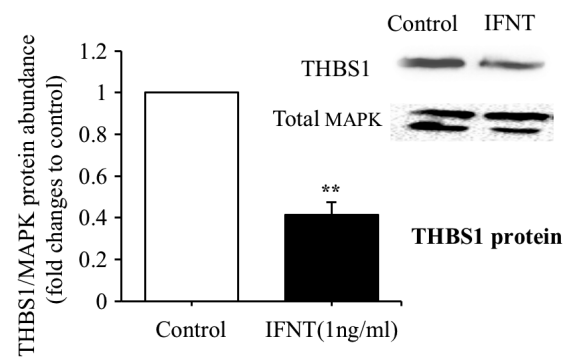

Figure 4 The effect of rolFNT on (A) TGFB1, THBS1, EDN1 and SERPINE1 mRNA and (B) THBS1 protein in LECs. (A) Serum-starved cells were incubated with either basal medium alone (control) or with rolFNT $(1 \mathrm{ng} / \mathrm{mL}$ ) for $24 \mathrm{~h}$. (B) Cells were incubated without (basal) or with rolFNT $(1 \mathrm{ng} / \mathrm{mL})$ for $48 \mathrm{~h}$, THBS1 protein was determined in cell extracts by Western blotting and normalized relative to the abundance of total MAPK (p44/42). Results are presented as the means \pm S.E.M. from 4 and 3 independent experiments for $A$ and $B$ respectively. Asterisks indicate significant $\left(* P<0.05,{ }^{* *} P<0.01,{ }^{* * *} P<0.001\right)$ differences from their respective controls. 

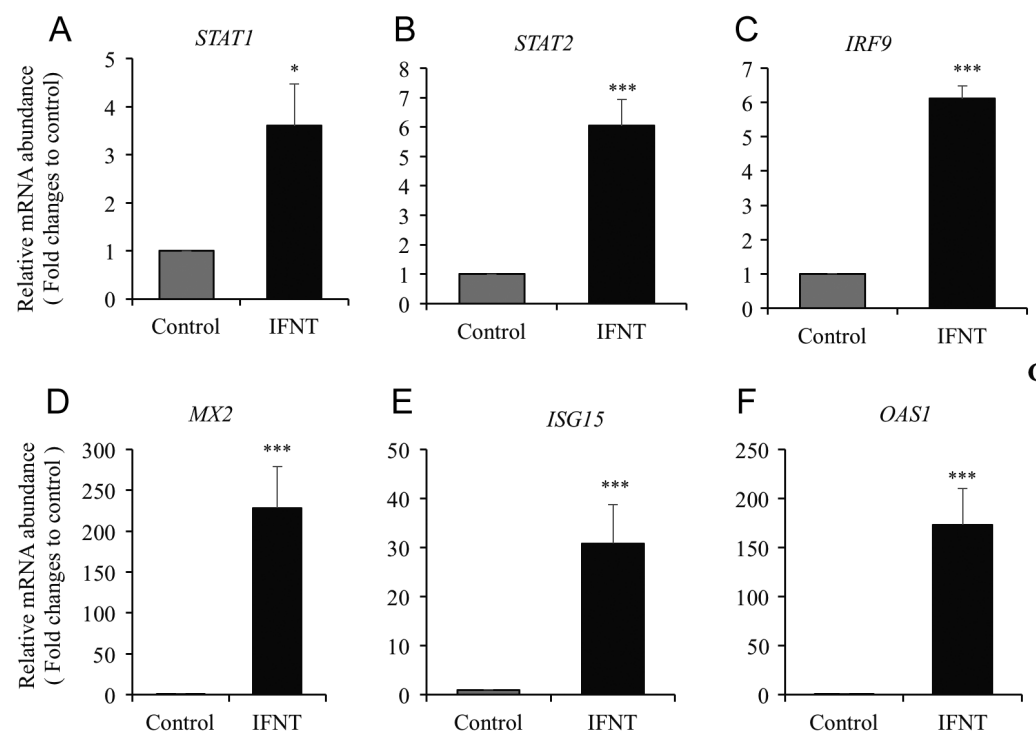

\begin{abstract}
Figure 5 IFNT-induced STAT1 (A), STAT2 (B), IRF9 (C), MX2 (D), ISG15 (E) and OAS1Y (F) mRNA in CL slices. Slices were incubated with either basal medium alone (control) or rolFNT $(1 \mathrm{ng} / \mathrm{mL})$ for $12 \mathrm{~h}$. Results are presented as the means \pm S.E.M. from 4 individual cows. Asterisks indicate significant $\left({ }^{*} P<0.05,{ }^{* *} P<0.01,{ }^{* * *} P<0.001\right)$ differences from their respective controls.
\end{abstract}

of the serine protease inhibitor family. PAI-1 inhibits tissue plasminogen activator and urokinase plasminogen activator, thus, SERPINE1 is a potent pro-fibrotic factor (Ghosh \& Vaughan 2012). In ewes, THBS1 and SERPINE1 were also shown to be concomitantly elevated during luteal regression, and inhibited during MRP (Romero et al. 2013). Furthermore, all of these genes (EDN1, THBS1, TGFB1 and SERPINE1) were reported to be highly expressed in bovine LECs (Levy et al. 2001, Zalman et al. 2012, Farberov \& Meidan 2016). In vitro response of luteal cells to IFNT was studied before by Romero and coworkers (Romero et al. 2013) using enriched ovine small, large and mixed luteal cells. The results obtained were not consistent with the expected effects of IFNT or pregnancy. For instance, neither SERPINE1 nor IL6 which were elevated during luteolysis in ewes and inhibited in the early pregnant $\mathrm{CL}$, were not

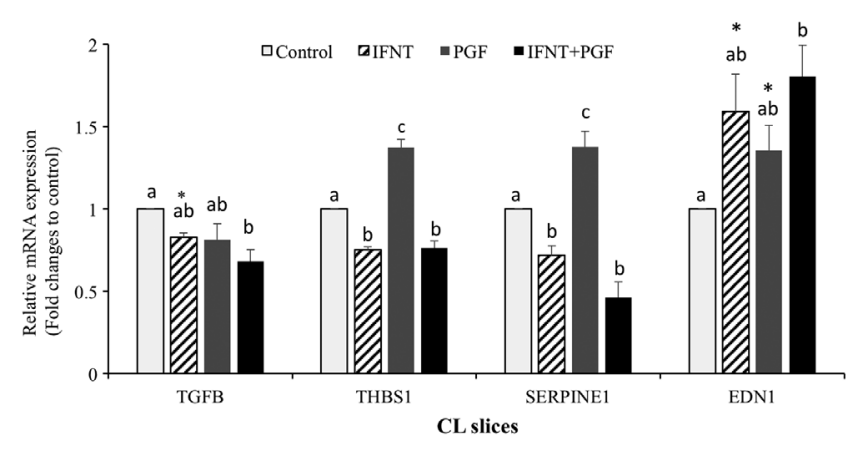

Figure 6 Luteolytic gene expression in $\mathrm{CL}$ slices in response to rolFNT $(1 \mathrm{ng} / \mathrm{mL})$, PGF2a $(30 \mathrm{nM})$ or their combination. Levels of TGFB1, THBS1, EDN1 and SERPINE1 were determined in CL slices incubated in basal media (control) or with treatments for $12 \mathrm{~h}$. Results are presented as the means \pm S.E.M. from 4 CLs each derived from individual cow. The different letters indicate significant statistical differences at $P<0.05$ analyzed using ANOVA followed by Bonferroni's post hoc multiple comparison test. significantly affected by IFNT in vitro in either of these cell preparations. The current study, using specifically enriched bovine LECs, showed that IFNT reduced EDN1, THBS1, TGFB1 and SERPINE1 mimicking the effect of early pregnancy (Costine et al. 2007, Romero et al. 2013, Przygrodzka et al. 2016). Importantly, in CL slices IFNT also abolished the stimulatory effect of PGF2a on THBS1 and SERPINE1. The reason why IFNT elevated EDN1 in slices remains enigmatic, especially as EDN1 is reduced during early pregnancy (Costine et al. 2007, Przygrodzka et al. 2016).

Pregnant ruminants have higher levels of basal PGF2a than cyclic animals do (Wilson et al. 1972, Zarco et al. 1988). However, oxytocin-induced PGF2a, released from endometrium, was significantly inhibited during pregnancy or IFNT infusion (Vallet et al. 1989, Vallet \& Lamming 1991, Meyer et al. 1995). This may be because IFNT can inhibit the majority of PGT-mediated release of PGF2a, but not the simple diffusion of PGF2a from endometrial luminal epithelial cells, as suggested by Banu and coworkers (Banu et al. 2010). These studies suggest that PGF2a can reach the CL during early pregnancy, thus requiring an anti-luteolytic mechanism at the level of the CL. In this context, our results demonstrating that IFNT can suppress luteolytic genes are physiologically important.

Precision-cut luteal slices and LECs were utilized to study the direct and functional roles of IFNT on bovine $\mathrm{CL}$. Precision-Cut CL slices represent an in vitro model that closely resembles the multi-cellular complexity as well as the structural and functional features of whole tissue. Use of precision-cut luteal slices to study luteal function has been validated in pigs (Przygrodzka et al. 2014). However, luteal slices have limitations such as restricted incubation times. In addition, slices are also an unsuitable model to study functional assays such as cell proliferation and cell transfection. $\mathrm{CL}$ is a highly 
vascular gland, where LECs comprise more than 50\% of all cell types within it (O'Shea et al. 1989). But in addition to their abundance, these cells are known to be active participants in the endocrine functions of the CL (Levy et al. 2001, Meidan et al. 2005), as highlighted again in this study. The stronger downregulation of luteolytic genes by IFNT in LECs may suggest that these cells are the primary target for IFNT to mediate its anti-luteolytic effects in bovine CL. However, the anti-luteolytic effects of IFNT on other bovine luteal cell types have not been studied yet and cannot be ruled out.

Collectively, the findings reported in the present study suggest that IFNT acts in the bovine CL via STAT1-IRF9dependent and independent pathways to elicit ISGs, type 1-associated genes and anti-luteolytic mechanisms. The increased viability of LECs induced by IFNT may constitute an additional mechanism to promote luteal cell survival, thus extending the luteal life span of cows during early pregnancy.

\section{Declaration of interest}

The authors declare that there is no conflict of interest that could be perceived as prejudicing the impartiality of the research reported.

\section{Funding}

This study is supported by a grant from Binational Agricultural Research \& Development (BARD) Fund - IS-4799-15, RM).

\section{References}

Andersen CL, Jensen JL \& Orntoft TF 2004 Normalization of real-time quantitative reverse transcription-PCR data: a model-based variance estimation approach to identify genes suited for normalization, applied to bladder and colon cancer data sets. Cancer Research 64 5245-5250. (doi:10.1158/0008-5472.CAN-04-0496)

Antoniazzi AQ, Webb BT, Romero JJ, Ashley RL, Smirnova NP, Henkes LE, Bott RC, Oliveira JF, Niswender GD, Bazer FW et al. 2013 Endocrine delivery of interferon tau protects the corpus luteum from prostaglandin F2 alpha-induced luteolysis in ewes. Biology of Reproduction $\mathbf{8 8}$ 141-112. (doi:10.1095/biolreprod.112.107110)

Apa R, Miceli F, de Feo D, Mastrandrea ML, Mancuso S, Napolitano M \& Lanzone A 1998 Endothelin-1 inhibits basal and human chorionic gonadotrophin-stimulated progesterone production. Human Reproduction 13 2425-2429. (doi:10.1093/humrep/13.9.2425)

Banu SK, Lee J, Stephen SD, Nithy TK \& Arosh JA 2010 Interferon tau regulates PGF2alpha release from the ovine endometrial epithelial cells via activation of novel JAK/EGFR/ERK/EGR-1 pathways. Molecular Endocrinology 24 2315-2330. (doi:10.1210/me.2010-0205)

Berisha B, Schams D, Rodler D, Sinowatz F \& Pfaffl MW 2016 Expression and localization of members of the thrombospondin family during final follicle maturation and corpus luteum formation and function in the bovine ovary. Journal of Reproduction and Development 62 501-510. (doi:10.1262/jrd.2016-056)

Bott RC, Ashley RL, Henkes LE, Antoniazzi AQ, Bruemmer JE, Niswender GD, Bazer FW, Spencer TE, Smirnova NP, Anthony RV et al. 2010 Uterine vein infusion of interferon tau (IFNT) extends luteal life span in ewes. Biology of Reproduction 82 725-735. (doi:10.1095/ biolreprod.109.079467)
Choudhary E, Sen A, Inskeep EK \& Flores JA 2005 Developmental sensitivity of the bovine corpus luteum to prostaglandin F2alpha (PGF2alpha) and endothelin-1 (ET-1): is ET-1 a mediator of the luteolytic actions of PGF2alpha or a tonic inhibitor of progesterone secretion? Biology of Reproduction 72 633-642. (doi:10.1095/biolreprod.104.034736)

Costine BA, Inskeep EK, Blemings KP, Flores JA \& Wilson ME 2007 Mechanisms of reduced luteal sensitivity to prostaglandin F2alpha during maternal recognition of pregnancy in ewes. Domestic Animal Endocrinology 32 106-121. (doi:10.1016/j.domaniend.2006.01.003)

Farberov S \& Meidan R 2014 Functions and transcriptional regulation of thrombospondins and their interrelationship with fibroblast growth factor-2 in bovine luteal cells. Biology of Reproduction 9158. (doi:10.1095/biolreprod.114.121020)

Farberov S \& Meidan R 2016 Thrombospondin-1 affects bovine luteal function via transforming growth factor-beta1-dependent and independent actions. Biology of Reproduction 94 25. (doi:10.1095/ biolreprod.115.135822)

Ghosh AK \& Vaughan DE 2012 PAI-1 in tissue fibrosis. Journal of Cellular Physiology 227 493-507. (doi:10.1002/jcp.22783)

Girsh E, Milvae RA, Wang W \& Meidan R 1996a Effect of endothelin-1 on bovine luteal cell function: role in prostaglandin F2alpha-induced antisteroidogenic action. Endocrinology 137 1306-1312. (doi:10.1210/ endo.137.4.8625904)

Girsh E, Wang W, Mamluk R, Arditi F, Friedman A, Milvae RA \& Meidan R $1996 b$ Regulation of endothelin-1 expression in the bovine corpus luteum: elevation by prostaglandin F 2 alpha. Endocrinology 137 5191-5196. (doi:10.1210/endo.137.12.8940334)

Hou X, Arvisais EW, Jiang C, Chen DB, Roy SK, Pate JL, Hansen TR, Rueda BR \& Davis JS 2008 Prostaglandin F2alpha stimulates the expression and secretion of transforming growth factor B1 via induction of the early growth response 1 gene (EGR1) in the bovine corpus luteum. Molecular Endocrinology 22 403-414. (doi:10.1210/me.2007-0272)

Kliem H, Welter H, Kraetzl WD, Steffl M, Meyer HH, Schams D \& Berisha B 2007 Expression and localisation of extracellular matrix degrading proteases and their inhibitors during the oestrous cycle and after induced luteolysis in the bovine corpus luteum. Reproduction 134 535-547. (doi:10.1530/REP-06-0172)

Lee J, McCracken JA, Banu SK, Rodriguez R, Nithy TK \& Arosh JA 2010 Transport of prostaglandin $\mathrm{F}$ (2alpha) pulses from the uterus to the ovary at the time of luteolysis in ruminants is regulated by prostaglandin transporter-mediated mechanisms. Endocrinology 151 3326-3335. (doi:10.1210/en.2009-0948)

Levy N, Gordin M, Mamluk R, Yanagisawa M, Smith MF, Hampton JH \& Meidan R 2001 Distinct cellular localization and regulation of endothelin-1 and endothelin-converting enzyme-1 expression in the bovine corpus luteum: implications for luteolysis. Endocrinology 142 5254-5260. (doi:10.1210/endo.142.12.8550)

Liu B, Mink S, Wong KA, Stein N, Getman C, Dempsey PW, Wu H \& Shuai K 2004 PIAS1 selectively inhibits interferon-inducible genes and is important in innate immunity. Nature Immunology 5 891-898. (doi:10.1038/ni1104)

Livak KJ \& Schmittgen TD 2001 Analysis of relative gene expression data using real-time quantitative PCR and the 2(-Delta Delta C(T)) Method. Methods 25 402-408. (doi:10.1006/meth.2001.1262)

Magata F, Shirasuna K, Struve K, Herzog K, Shimizu T, Bollwein H \& Miyamoto A 2012 Gene expressions in the persistent corpus luteum of postpartum dairy cows: distinct profiles from the corpora lutea of the estrous cycle and pregnancy. Journal of Reproduction and Development 58 445-452. (doi:10.1262/jrd.2011-049)

Mamluk R, Chen D, Greber Y, Davis JS \& Meidan R 1998 Characterization of messenger ribonucleic acid expression for prostaglandin F2 alpha and luteinizing hormone receptors in various bovine luteal cell types. Biology of Reproduction 58 849-856. (doi:10.1095/biolreprod58.3.849)

Maroni D \& Davis JS 2012 Transforming growth factor Beta 1 stimulates profibrotic activities of luteal fibroblasts in cows. Biology of Reproduction 87 127. (doi:10.1093/biolreprod/87.s1.127)

Matsuyama S, Kojima T, Kato S \& Kimura K 2012 Relationship between quantity of IFNT estimated by IFN-stimulated gene expression in peripheral blood mononuclear cells and bovine embryonic mortality after Al or ET. Reproductive Biology and Endocrinology 1021. (doi:10.1186/1477-7827-10-21) 
Meidan R, Levy N, Kisliouk T, Podlovny L, Rusiansky M \& Klipper E 2005 The yin and yang of corpus luteum-derived endothelial cells: balancing life and death. Domestic Animal Endocrinology 29 318-328. (doi:10.1016/j.domaniend.2005.04.003)

Meidan R, Girsh E, Malmuk R, Levy N \& Farberov S 2017. Luteolysis in ruminants: past concepts, new insights, and persisting challenges. In The Life Cycle of the Corpus Luteum, ch 9, pp 159-182. Ed. R MeidanR New York: Springer Nature.

Meyer MD, Hansen PJ, Thatcher WW, Drost M, Badinga L, Roberts RM, Li J, Ott TL \& Bazer FW 1995 Extension of corpus luteum lifespan and reduction of uterine secretion of prostaglandin F2 alpha of cows in response to recombinant interferon-tau. Journal of Dairy Science $\mathbf{7 8}$ 1921-1931. (doi:10.3168/jds.S0022-0302(95)76817-5)

Miyamoto A, Kobayashi S, Arata S, Ohtani M, Fukui Y \& Schams D 1997 Prostaglandin F2 alpha promotes the inhibitory action of endothelin-1 on the bovine luteal function in vitro. Journal of Endocrinology 152 R7R11. (doi:10.1677/joe.0.152R007)

Mondal M, Schilling B, Folger J, Steibel JP, Buchnick H, Zalman Y, Ireland JJ, Meidan R \& Smith GW 2011 Deciphering the luteal transcriptome: potential mechanisms mediating stage-specific luteolytic response of the corpus luteum to prostaglandin $F(2)$ alpha. Physiological Genomics 43 447-456. (doi:10.1152/ physiolgenomics.00155.2010)

Munarriz E, Barcaroli D, Stephanou A, Townsend PA, Maisse C, Terrinoni A, Neale MH, Martin SJ, Latchman DS, Knight RA et al. 2004 PIAS-1 is a checkpoint regulator which affects exit from G1 and G2 by sumoylation of p73. Molecular and Cellular Biology 24 10593-10610. (doi:10.1128/ MCB.24.24.10593-10610.2004)

Niswender GD, Juengel JL, Silva PJ, Rollyson MK \& McIntush EW 2000 Mechanisms controlling the function and life span of the corpus luteum. Physiological Reviews 80 1-29.

Nitta A, Shirasuna K, Haneda S, Matsui M, Shimizu T, Matsuyama S, Kimura K, Bollwein H \& Miyamoto A 2011 Possible involvement of IFNT in lymphangiogenesis in the corpus luteum during the maternal recognition period in the cow. Reproduction 142 879-892. (doi:10.1530/ REP-11-0157)

O'Shea JD, Rodgers RJ \& D'Occhio MJ 1989 Cellular composition of the cyclic corpus luteum of the cow. Journals of Reproduction and Fertility 85 483-487. (doi:10.1530/jrf.0.0850483)

Ohtani M, Kobayashi S, Miyamoto A, Hayashi K \& Fukui Y 1998 Realtime relationships between intraluteal and plasma concentrations of endothelin, oxytocin, and progesterone during prostaglandin F2alphainduced luteolysis in the cow. Biology of Reproduction 58 103-108. (doi:10.1095/biolreprod58.1.103)

Oliveira JF, Henkes LE, Ashley RL, Purcell SH, Smirnova NP, Veeramachaneni DN, Anthony RV \& Hansen TR 2008 Expression of interferon (IFN)-stimulated genes in extrauterine tissues during early pregnancy in sheep is the consequence of endocrine IFN-tau release from the uterine vein. Endocrinology 149 1252-1259. (doi:10.1210/ en.2007-0863)

Przygrodzka E, Lopinska M \& Ziecik AJ 2014 Precision-cut luteal slices: a promising approach for studying luteal function in pigs. Reproductive Biology 14 243-247. (doi:10.1016/j.repbio.2014.04.001)

Przygrodzka E, Kaczmarek MM, Kaczynski P \& Ziecik AJ 2016 Steroid hormones, prostanoids, and angiogenic systems during rescue of the corpus luteum in pigs. Reproduction 151 135-147. (doi:10.1530/REP15-0332)

Roberts RM, Ealy AD, Alexenko AP, Han CS \& Ezashi T 1999 Trophoblast interferons. Placenta 20 259-264. (doi:10.1053/plac.1998.0381)

Romero JJ, Antoniazzi AQ, Smirnova NP, Webb BT, Yu F, Davis JS \& Hansen TR 2013 Pregnancy-associated genes contribute to antiluteolytic mechanisms in ovine corpus luteum. Physiological Genomics 45 1095-1108. (doi:10.1152/physiolgenomics.00082.2013)

Romero JJ, Antoniazzi AQ, Nett TM, Ashley RL, Webb BT, Smirnova NP, Bott RC, Bruemmer JE, Bazer FW, Anthony RV et al. 2015 Temporal release, paracrine and endocrine actions of ovine conceptus-derived interferon-Tau during early pregnancy. Biology of Reproduction 93146. (doi:10.1095/biolreprod.115.132860)

Rosenfeld CS, Han CS, Alexenko AP, Spencer TE \& Roberts RM 2002 Expression of interferon receptor subunits, IFNAR1 and IFNAR2, in the ovine uterus. Biology of Reproduction 67 847-853. (doi:10.1095/ biolreprod.102.004267)

Schams D \& Berisha B 2004 Regulation of corpus luteum function in cattle-an overview. Reproduction in Domestic Animals 39 241-251. (doi:10.1111/j.1439-0531.2004.00509.x)

Schmittgen TD \& Livak KJ 2008 Analyzing real-time PCR data by the comparative C(T) method. Nature Protocols 3 1101-1108. (doi:10.1038/ nprot.2008.73)

Sharrocks AD 2006 PIAS proteins and transcriptional regulation-more than just SUMO E3 ligases? Genes and Development 20 754-758. (doi:10.1101/gad.1421006)

Shirasuna K, Asaoka H, Acosta TJ, Wijayagunawardane MP, Matsui M, Ohtani M \& Miyamoto A 2004 Endothelin-1 within the corpus luteum during spontaneous luteolysis in the cow: local interaction with prostaglandin F2alpha and angiotensin II. Journal of Cardiovascular Pharmacology 44 (Supplement 1) S252-S255. (doi:10.1097/01. fjc.0000166322.76376.60)

Shirasuna K, Yamamoto D, Morota K, Shimizu T, Matsui M \& Miyamoto A 2008 Prostaglandin F 2 alpha stimulates endothelial nitric oxide synthase depending on the existence of bovine granulosa cells: analysis by coculture system of endothelial cells, smooth muscle cells and granulosa cells. Reproduction in Domestic Animals 43 592-598. (doi:10.1111/ j.1439-0531.2007.00957.x)

Shirasuna K, Nitta A, Sineenard J, Shimizu T, Bollwein H \& Miyamoto A 2012 Vascular and immune regulation of corpus luteum development, maintenance, and regression in the cow. Domestic Animal Endocrinology 43 198-211. (doi:10.1016/j.domaniend.2012.03.007)

Shirasuna K, Matsumoto H, Matsuyama S, Kimura K, Bollwein H \& Miyamoto A 2015 Possible role of IFNT on the bovine corpus luteum and neutrophils during the early pregnancy. Reproduction. 150 217-225. (doi:10.1530/REP-15-0085)

Smith GW, Gentry PC, Bao B, Long DK, Roberts RM \& Smith MF 1997 Control of extracellular matrix remodelling within ovarian tissues: localization and regulation of gene expression of plasminogen activator inhibitor type-1 within the ovine corpus luteum. Journals of Reproduction and Fertility 110 107-114. (doi:10.1530/jrf.0.1100107)

Spencer TE, Ott TL \& Bazer FW 1996 tau-Interferon: pregnancy recognition signal in ruminants. Proceedings of the Society for Experimental Biology and Medicine 213 215-229. (doi:10.3181/00379727-213-44053)

Staggs KL, Austin KJ, Johnson GA, Teixeira MG, Talbott CT, Dooley VA \& Hansen TR 1998 Complex induction of bovine uterine proteins by interferon-tau. Biology of Reproduction 59 293-297. (doi:10.1095/ biolreprod59.2.293)

Takahashi H, Sawai K, Minamihashi A, Kageyama S MS, Hirayama H \& OSG M 2007 Expression profile and protein secretion of bovine interferon T on days 12 to 28 in early pregnancy. Reproduction, Fertility and Development 1 201-202. (doi:10.1071/RDv19n1Ab170)

Thatcher WW, Hansen PJ, Gross TS, Helmer SD, Plante C \& Bazer FW 1989 Antiluteolytic effects of bovine trophoblast protein-1. Journal of Reproduction and Fertility. Supplement 37 91-99.

Vallet JL \& Lamming GE 1991 Ovine conceptus secretory proteins and bovine recombinant interferon alpha (1)-1 decrease endometrial oxytocin receptor concentrations in cyclic and progesterone-treated ovariectomized ewes. Journal of Endocrinology 131 475-482. (doi:10.1677/joe.0.1310475)

Vallet JL, Gross TS, Fliss MF \& Bazer FW 1989 Effects of pregnancy, oxytocin, ovine trophoblast protein-1 and their interactions on endometrial production of prostaglandin F2 alpha in vitro in perifusion chambers. Prostaglandins 38 113-124. (doi:10.1016/0090-6980(89)90020-8)

Vitorino Carvalho A, Eozenou C, Healey GD, Forde N, Reinaud P, Chebrout M, Gall L, Rodde N, Padilla AL, Delville CG et al. 2016 Analysis of STAT1 expression and biological activity reveals interferontau-dependent STAT1-regulated SOCS genes in the bovine endometrium. Reproduction, Fertility and Development 28 459-474. (doi:10.1071/ RD14034)

Wilson L Jr, Butcher RL \& Inskeep EK 1972 Prostaglandin F2alpha in the uterus of ewes during early pregnancy. Prostaglandins 1 479-482. (doi:10.1016/0090-6980(72)90017-2)

Yang L, Wang XL, Wan PC, Zhang LY, Wu Y, Tang DW \& Zeng SM 2010 Up-regulation of expression of interferon-stimulated gene 15 in the 
bovine corpus luteum during early pregnancy. Journal of Dairy Science 93 1000-1011. (doi:10.3168/jds.2009-2529)

Zalman Y, Klipper E, Farberov S, Mondal M, Wee G, Folger JK, Smith GW \& Meidan R 2012 Regulation of angiogenesis-related prostaglandin f2alpha-induced genes in the bovine corpus luteum. Biology of Reproduction 86 92. (doi:10.1095/biolreprod.111.095067)

Zannoni A, Bernardini C, Rada T, Ribeiro LA, Forni M \& Bacci ML 2007 Prostaglandin $\mathrm{F} 2$-alpha receptor ( $\mathrm{FPr}$ ) expression on porcine corpus luteum microvascular endothelial cells (pCL-MVECs). Reproductive Biology and Endocrinology 5 31. (doi:10.1186/1477-7827-5-31)

Zarco L, Stabenfeldt GH, Basu S, Bradford GE \& Kindahl H 1988 Modification of prostaglandin F-2 alpha synthesis and release in the ewe during the initial establishment of pregnancy. Journal of Reproduction and Fertility 83 527-536. (doi:10.1530/jrf.0.0830527)

Received 11 May 2017

First decision 31 May 2017

Revised manuscript received 27 June 2017

Accepted 21 July 2017 